\title{
TRAUMA, TERNURA E UMA (NÃO TÃO) NOVA ÉTICA EM PSICANÁLISE
}

\author{
Aline Spaciari Matioli \\ Universidade Estadual de Maringá \\ Instituto Federal do Paraná \\ Viviana Carola Velasco Martínez \\ Universidade Estadual de Maringá
}

Recebido em: 29/10/2019

$1^{a}$ revisão em: 12/12/2019

Aceito em: 20/01/2020

Maciel Jr., A. (Ed.). (2018). Trauma e ternura: A ética em Sándor Ferenczi. Rio de Janeiro, RJ:

Editora 7 Letras.

\section{RESENHA}

Por que estudar Ferenczi hoje? O que justifica a recente expansão de artigos, dissertações, teses e livros inspirados em suas contribuições teórico-clínicas? É na intenção de lançar um pouco de luz a este movimento, que iniciamos com uma breve explicação.

Sándor Ferenczi foi o mais íntimo colaborador do pai da psicanálise. Entusiasta, inteligente e sensível eram adjetivos utilizados pelos psicanalistas de seu tempo para defini-lo (Haynal, 1995). Freud também tece elogios públicos ao discípulo e amigo, à originalidade e à riqueza de suas ideias. Em homenagem póstuma a Ferenczi, sublinha seu talento e declara que seus trabalhos "tornaram todos os analistas seus discípulos" (Freud, 1933/1996c, p.224). Mas diferente de Freud (1905/1996a), que chegou a cogitar um limite para aplicação de seu método supostamente contraindicado para as formas de organização psíquica não fundadas sobre o recalcamento - Ferenczi acolheu em sua clínica toda uma gama de pacientes resistentes e refratários à técnica psicanalítica tradicional. Para tanto, aventurou-se em seus experimentos técnicos, sendo a técnica ativa a mais conhecida. Por meio de injunções e proibições, Ferenczi (1921/2011b) buscou provocar um incremento da angústia que pudesse favorecer a emergência de conteúdos reprimidos nas análises estagnadas, estratégia inspirada e a priori apoiada por Freud. Atento e sensível ao sofrimento humano, aos poucos, Ferenczi (1928/2011d) pôde observar que a indiferença, a abstinência e o excesso de neutralidade amiúde empregados nas análises tinham um efeito iatrogênico, pois 
capazes de reativar vivências infantis traumáticas pela atualização de uma experiência de submissão outrora vivida. Foi o que o levou a abdicar da técnica ativa e a postular a necessidade de adaptação do analista e a insistir na importância do tato, da empatia, da sinceridade e da sensibilidade.

De sua experiência clínica com os mais fragilizados nasce sua concepção de trauma desestruturante apresentado na famosa conferência Confusão de línguas entre os adultos e a criança, proferida no Congresso de Wiesbaden em 1932. Esta exposição resultou em um desentendimento com Freud à época, o que contribuiu para décadas de ostracismo desse brilhante clínico da primeira geração (Gondar, 2016). Crítico ao que pareceu um simples resgate de sua neurótica, Freud deixou de ver a dimensão relacional na traumatogênese ferencziana, onde o mais importante não é a vivência da violência ou abuso sexual em si, mas a desautorização do sofrimento da vítima: "o pior é realmente a negação, a afirmação de que não aconteceu nada, de que não houve sofrimento ou até mesmo ser espancado ou repreendido..." (Ferenczi, 1931/2011e, p.91), é isto o que torna o trauma patogênico.

Para Gondar (2016), o recente movimento de resgate das ideias de Ferenczi tem estreita relação com as manifestações clínicas contemporâneas, "mais marcadas pelo trauma, pela dissociação psíquica, pela anestesia e pela identificação com o agressor do que pelos conflitos edipianos e o recalcamento da sexualidade" (p.137). A autora cita o pânico, a depressão, as compulsões e os sintomas psicossomáticos, e dentro desse mesmo espectro de fenômenos podemos certamente acrescentara anorexia, as adicções e a autolesão. Eis algumas das razões que nos incitam à leitura desta obra, que além de abordar conceitos fundamentais da teoria ferencziana do trauma, como desmentido, identificação ao agressor, cisão psíquica e progressão traumática, também nos brinda com reflexões teóricas e clínicas sustentadas na atual necessidade de elasticidade da técnica proposta por Ferenczi em 1928, as quais nos auxiliam na árdua, mas imprescindível tarefa de acolher os assim chamados pacientes difíceis. Dito isso, e sem mais delongas, é hora de nos atermos à obra resenhada.

Auterives Maciel, organizador do livro que nos ocupamos nesta resenha, não poderia ter escolhido um título mais expressivo, pois os termos trauma e ternura fazem alusão a uma das discussões mais caras a Ferenczi: a sua teoria do trauma, vimos, e a consequente postura ética necessária para esta clínica trágica. Trata-se de uma obra escrita a várias mãos, que tem como um de seus méritos a colaboração de pesquisadores brasileiros, de diferentes universidades do país, que há tempos se dedicam aos escritos ferenczianos.

No capítulo de abertura, Nas cinzas da castástrofe, surge a criança, Eliana Reis e Leila G. L. Mendonça abordam as transformações das famílias engendradas pela conjuntura socioeconômica atual e destacam a dificuldade dos pais investirem libidinalmente nas crianças, que estão a cada dia mais próximas àquela descrita por Ferenczi, "a criança mal-acolhida", e cada vez mais distantes daquela descrita 
por Freud, "sua majestade, o bebê". Tal fato produz efeitos catastróficos para o psiquismo, que fica à mercê dos transbordamentos pulsionais, e assim as excitações são descarregadas de forma direta, ora por meio de ações destrutivas contra o outro, ora contra si mesmo, como atestam os fenômenos psicossomáticos e a autolesão. Na mesma vertente, em Pulsão de morte e teoria do trauma, Marcelo Bernstein, Letícia Cerqueira e Ana Maria Rugde debatem a metapsicologia da pulsão de morte em Ferenczi que, apesar de partir da ideia freudiana de uma pulsão inata, relativiza a importância das tendências biológicas ao atribuir a uma configuração relacional a intensidade pulsional. Logo, quando afetada pelo ódio e aversão provenientes da própria mãe (ou de quem cuida), a criança tende a desenvolver doenças que colocam em risco a sua existência em face à internalização do desejo de morte, o que está na gênese das tendências inconscientes de autodestruição que a clínica atual não cessa em testemunhar.

No capítulo Trauma, descrédito e masoquismo em Ferenczi, Teresa Pinheiro e Diana Viana apresentam uma leitura da subjetividade feminina a partir das pistas deixadas por Ferenczi em diferentes trabalhos. Com a exposição do caso clínico "A 'indesistível' Ana", destacam a capacidade da mulher suportar o sofrimento, como um trunfo masoquista de onde retira sua força e afirma sua identidade, pois sofrimento e sacrifício se entrelaçam em uma virada altruísta que confere prazer narcísico.

Em Trauma, autotomia e (re)criação: a adolescência como trabalho de perlaboração da puberdade, Perla Klautau, Gilson G. Lopes e Catarina B. Leal traçam um paralelo entre a metáfora zoológica da autotomia (referente à autoamputação de partes do corpo feita por certos animais como meio de defesa) descrita por Ferenczi, e a chegada da adolescência, entendida como um momento potencialmente traumático, pois o púbere precisa dar conta tanto das alterações corporais e hormonais que afetam sua identidade, quanto do despertar das pulsões adormecidas no período de latência. Para sobreviver à intensidade dessas transformações é preciso deixar cair uma parte de si - o infantil ancorado nos ideais parentais - o que exige um intenso trabalho psíquico de (re)significação para ascender ao novo status.

Leandro Câmara, Regina Herzog e Fernanda Canavêz em A palavra e o corpo: impressão e expressão na teoria ferenczina asseveram que, na obra do psicanalista húngaro, corpo e linguagem verbal não são opostos. Embora a psicanálise tradicionalmente considere a linguagem como a forma de expressão privilegiada na análise, a clínica não se reduz a ela, o que implica na necessidade de valorizar mais as manifestações corporais que emergem no setting. Foi o que fez Ferenczi ao apontar para uma diferença de grau e não de natureza nessas duas formas de expressão, pois haveria um continuum entre elas o que impediria de reduzir à linguagem verbal à multiplicidade expressiva do corpo na clínica. Dito de outro modo: para trabalhar nos limites da representação é preciso ir além e também escutar o que nos dizem as manifestações corporais e tudo o mais que destoa do que estamos habituados a lidar em nossas práticas. 
Julio Verztman e Thais Klein, em Desenvolvimento e processo como operadores para Ferenczi e Winnicott, discutem os estágios do desenvolvimento do sentido de realidade em Ferenczi, que culmina em uma distinção crescente entre o si mesmo e o mundo externo. Winnicott teria dado continuidade a esta ideia ao articular a noção de desenvolvimento à temporalidade, esse vivido como um processo contínuo e não-linear por meio do qual algumas potencialidades do bebê se atualizam e ganham forma. Destacam, contudo, que este é um debate inacabado, termos como desenvolvimento, tempo e processo ainda exigirão um árduo trabalho de elaboração e criação por parte de outros psicanalistas.

Na segunda metade do livro temos, em sequência, três capítulos que tratam da noção de empatia em Ferenczi. Primeiramente, Joana V. Novaes, Lilian Barreto e Paula F. W. Hartmann, no ensaio Humanização, empatia e afetividade: considerações acerca do paciente renal crônico tecem críticas à objetificação dos pacientes feita pela medicina moderna. Tendo como exemplo prático a doença renal crônica (DRC), afirmam que o excesso de neutralidade e objetividade dos profissionais, amiúde uma defesa contra a angústia e a impotência frente à possibilidade da morte dos pacientes, favorece a desumanização do atendimento, o que prejudica a adesão ao tratamento. Para reverter este cenário defendem o acolhimento afetivo, pautado na empatia genuína com vistas à humanização. Já Auterives Maciel e Tereza C. F. Novaes, em Einfühlung: a arte do sentir com, analisam a empatia sob a perspectiva estética de Worringer e mostram como os impasses da técnica ativa, inócua com os pacientes que foram vítima de violência na infância, levaram Ferenczi a repensar sua técnica, tornando-a mais flexível, sustentada na ética/estética do "sentir com" que se contrapõe à rigidez moral do método convencional. Ainda dentro do tema da empatia, Bartholomeu A. Vieira e Daniel Kuperman em Limites e atualidade da empatia revisitam os três princípios da ética do cuidado propostos por Kupermann (2017) em seu livro Estilos do Cuidado, a saber: a hospitalidade (capacidade de acolher o paciente), a empatia (o sentir com) e a saúde do analista (cuidar de si para cuidar do outro), e assim embasados argumentam que frente ao paciente traumatizado, cujo psiquismo sofreu os efeitos da clivagem, a empatia por parte do analista é fundamental, pois favorece a conexão com a parte sensível e clivada, inacessível pela técnica interpretativa que, pelo contrário, poderia produzir mal-estar e submissão.

Como um desdobramento da empatia no campo da técnica, temos a linguagem da ternura como objeto de dois capítulos com enfoques diferentes. Jô Gondar e Flora Tucci em Ética e jogos de linguagem na obra ferencziana nos convidam a ver, nas entrelinhas dos textos de Ferenczi, sua disponibilidade imanente de se colocar no lugar do outro, o que lhe permitiu legitimar a dor e dar voz aqueles que foram silenciados pela violência dos mais fortes: como as mulheres, destituídas do prazer nas relações sexuais em uma cultura machista e patriarcal, tema abordado no primeiro texto psicanalítico de Ferenczi (1908/2011a), Do alcance da ejaculação precoce, e as crianças, vítimas da paixão dos adultos, tema central de Confusão de línguas (1932/2011f). Esta postura empática frente aos mais fragilizados, presente do início ao fim de sua obra, também possibilitou compreender a linguagem da 
ternura - o que inclui o não verbal, como os gestos, o tom de voz, a mímica - e entrar no jogo do paciente, dirigindo-se à criança traumatizada existente em cada adulto, adaptando-se às suas necessidades para, enfim, ser capaz de acessar as experiências traumáticas vividas em tempos precoces. No capítulo seguinte, $A$ língua menor da ternura "Confusão de língua" e bilinguismo em Psicanálise, Auterives Maciel, Mariana T. Barbosa e Mauro S. Carvalho explicam que, para Ferenczi, estar atento à linguagem da ternura é ouvir a criança que habita o adulto, pois é somente esta atmosfera de confiança que permite o acesso à parte infantil clivada pelo efeito da identificação ao agressor quando da vivência traumática. Entrar em contato com a linguagem da ternura só seria possível mediante uma postura sensível e sincera por parte do analista que tivesse superado suas próprias resistências em uma análise pessoal profunda. Não à toa que, a recomendação de Freud (1912/1996b) sobre a importância do analista ser analisado, seja tomada por Ferenczi (1927/2011c) como a segunda regra fundamental da psicanálise, condição indispensável para o exercício da primeira regra, relativa à escuta da associação livre do paciente.

Para completar as discussões iniciadas no capítulo anterior, no derradeiro Pensara experiência traumática: a construção da verdade pela via da confiança, Auterives Maciel e Eduardo Ledo indicam como Ferenczi subverte a técnica clássica, sustentada na associação livre e na neutralidade do analista, ao defender a circulação afetiva no setting. Esta, por sua vez, estaria balizada em uma relação de confiança indispensável para a clínica do trauma, pois marca o contraste entre o presente e o passado insuportável desfazendo, assim, o desmentido. Além de propor inovações técnicas como, por exemplo, a empatia, a elasticidade, a confiança e a benevolência, o clínico húngaro ousou denunciar à hipocrisia profissional dos analistas de seu tempo o que não foi bem visto por grande parte da comunidade psicanalítica da época.

Inspirados em Sándor Ferenczi, diferentes pesquisadores e analistas-pesquisadores compartilham seus conhecimentos teórico-clínicos neste livro de temáticas bastante diversas. Intercessões com outros autores, como Winnicott, Worringer, Wittgenstein, Delleuse e Guattari se mesclam a reflexões precisas sobre os conceitos ferenczianos, enriquecidos com a capacidade criativa dos autores que os ampliam e aprofundam em um estilo de escrita envolvente. Um após o outro os textos relevam o tesouro quase perdido por uma confusão de línguas entre Freud e Ferenczi (Baracat, Abrão, \& Martínez, 2017), e pela difamação realizada por Ernest Jones ao depreciar seu estado mental na biografia de Freud (Mautner, 1996), fato que impediu, por mais de meio século, o acesso às suas ideias hoje reconhecidamente valiosas para a clínica contemporânea, repleta dos ditos casos difíceis sobre os quais o psicanalista húngaro se debruçou nos primórdios da psicanálise.

Aproveitemos, portanto, a oportunidade para aprender com Ferenczi e seus interlocutores, e quem sabe nos inspirarmos em sua postura transgressora para questionar a imutabilidade da técnica usualmente defendida por correntes 
psicanalíticas mais ortodoxas, que muitas vezes aprisionam a prática psicanalítica dentro de limites rígidos. Este é o caso de algumas escolas filiadas à I.P.A. (International Psychoanalytical Association) e sua exigência normativa de análises didáticas nos moldes do início do século XX. Paradoxalmente, a crítica a este modelo de análise teve início com o próprio Ferenczi, primeiro idealizador da instituição criada em 1910 a pedido de Freud. De seu ponto de vista, essas análises eram insuficientes para o candidato à psicanalista, que face à sua responsabilidade frente ao sofrimento humano, deveria trabalhar de forma profunda suas fraquezas e seu narcisismo para que tais elementos não viessem a interferir negativamente nas análises (Ferenczi, 1927/2011c). Eis mais um exemplo de sua postura ética, que o levou a afirmações no mínino embaraçosas, a respeito das quais ele estava ciente do impacto: "o fato é que sou, em geral, bastante conhecido como um espírito inquieto ou, como me foi recentemente dito em Oxford, como o enfant terrible da psicanálise" (Ferenczi, 1931/2011e, p. 80).

Por fim, e sem a pretensão de exaurir a diversidade e profundidade dos temas apresentados nesses doze capítulos, poder-se-ia dizer que a leitura dessa obra permite ventilar as certezas sobre o modo tradicional de se conduzir a clínica, o que se reflete em uma práxis mais flexível e também atenta às múltiplas formas de linguagem presentes no setting - da verbal à não verbal, da paixão à ternura -, pois ancorada na ética do "sentir com" inaugurada por Ferenczi, que se alinha às necessidades dos pacientes severamente traumatizados.

\section{REFERÊNCIAS}

Baracat, J. Abrão, J. L. F., Martínez, V. C. V. (2017). Confusão de línguas entre Freud e Ferenczi: trauma, sedução e as contribuições de Jean Laplanche. Memorandum, 33, 68-89.

Ferenczi, S. (2011a). Do alcance da ejaculação precoce. In Psicanálise I- Obras completas de Sándor Ferenczi (Á. Cabral, Trad., 2a ed., Vol. 1, pp. 1-4). São Paulo, SP: Editora WMF Martins Fontes. (Trabalho original publicado em 1908).

Ferenczi, S. (2011b). Prolongamentos da "técnica ativa" em psicanálise. In Psicanálise III Obras completas de Sándor Ferenczi (Á. Cabral, Trad., 2a ed., Vol. 3, pp. 117-135). (2ed). São Paulo, SP: Editora WMF Martins Fontes. (Trabalho original publicado em 1927)

Ferenczi, S. (2011c). O problema do fim da análise. In Psicanálise IV - Obras completas de Sándor Ferenczi (Á. Cabral, Trad., 2a ed., Vol. 4, pp. 17-27). São Paulo, SP: Editora WMF Martins Fontes. (Trabalho original publicado em 1927)

Ferenczi, S. (2011d). Elasticidade da técnica psicanalítica. In Psicanálise IV - Obras completas de Sándor Ferenczi (Á. Cabral, Trad., 2a ed., Vol. 4, pp. 29-42). São Paulo, SP: Editora WMF Martins Fontes. (Trabalho original publicado em 1928).

Ferenczi, S. (2011e). Análise de crianças com adultos. In Psicanálise IV - Obras completas de Sándor Ferenczi (Á. Cabral, Trad., 2a ed., Vol. 4, pp. 79-95). São Paulo, SP: Editora WMF Martins Fontes. (Trabalho original publicado em 1931). 
Ferenczi, S. (2011f). Confusão de línguas entre os adultos e a criança. In Psicanálise IV Obras completas de Sándor Ferenczi (Á. Cabral, Trad., 2a ed., Vol. 4, pp. 111-121). São Paulo, SP: Editora WMF Martins Fontes. (Trabalho original publicado em 1932).

Freud, S. (1996a). Sobre a psicoterapia. In Edição standard das obras completas de Sigmund Freud (J. Salomão, Trad., Volume VII, pp. 244-254). Rio de Janeiro, RJ: Imago Editora Ltda. (Trabalho original publicado em 1905).

Freud, S. (1996b). Recomendações aos médicos que exercem a psicanálise. In Edição standard brasileira das obras completas de Sigmund Freud (J. Salomão, Trad., Volume XII, pp.125-133). Rio de Janeiro, RJ: Imago Editora Ltda. (Trabalho original publicado em 1912).

Freud, S. (1996c). Sándor Ferenczi. In Edição standard brasileira das obras completas de Sigmund Freud (J. Salomão, Trad., Volume XXII, pp. 223-225). Rio de Janeiro, RJ: Imago Editora Ltda. (Trabalho original publicado em 1933)

Gondar, J. (2016). Trauma, Cultura e Criação: Ferenczi com Christoph Türcke. Revista Tempo Psicanalítico, 48(2), 135-148.

Haynal, A. (1995). A técnica em questão: Controvérsias em psicanálise: De Freud e Ferenczi a Michael Balint. São Paulo, SP: Casa do Psicólogo.

Kupermann, D. (2017). Estilos do cuidado: a psicanálise e o traumático. São Paulo, SP: Editora Zagodoni.

Mautner, A.V. (1996). Ferenczi: Cultura e história. In Katz, C.S. (Ed.), Ferenczi: História, teoria e técnica. (pp. 15-42). São Paulo, SP: Editora 34.

\section{SOBRE AS AUTORAS}

Aline Spaciari Matioli é psicóloga, mestre e doutoranda pelo Programa de Pós-Graduação em Psicologia na linha de pesquisa Psicanálise e Civilização pela Universidade Estadual de Maringá. Psicóloga do Instituto Federal do Paraná- Campus Ivaiporã.

E-mail: prof alinematioli@hotmail.com

(1) https://orcid.org/0000-0002-4077-2246

Viviana Carola Velasco Martínez é professora doutora do Departamento de Psicologia e do Programa de Pós-Graduação em Psicologia, na linha de pesquisa Psicanálise e Civilização da Universidade Estadual de Maringá. Coordenadora do Laboratório de Estudos e Pesquisa em Psicanálise e Civilização (LEPPSIC/UEM).

E-mail: vcvmartinez@hotmail.com

(3) https://orcid.org/0000-0002-5389-7988 